\title{
CORRECTION
}

\section{Correction: TNF/TNFR signal transduction pathway-mediated anti-apoptosis and anti- inflammatory effects of sodium ferulate on IL-1 $\beta$ - induced rat osteoarthritis chondrocytes in vitro}

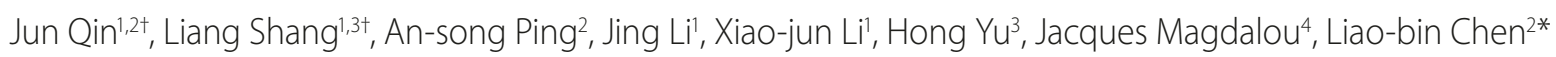 \\ and Hui Wang ${ }^{\text {* }}$
}

See related research by Qin et al., http://arthritis-research.com/content/14/6/R242

\section{Correction \\ After publication of our recent article [1], it was brought to our attention that an inaccurate observation was made in the Results section. We stated that different concen- trations of SF have no effect on normal chondrocytes viability. However, Figure 1 demonstrates that SF concen- trations 500 and $1000 \mu \mathrm{mol} / \mathrm{L}$ significantly increase chon- drocytes viability compared with the control group. The following sentence has now been deleted from the Results section: "All of these results show that different concentrations of SF from 125 to $1,000 \mu \mathrm{mol} / \mathrm{l}$ have no effect on normal chondrocyte viability".}

\section{Competing interests}

The authors declare that they have no competing interests.

\section{Author details}

'Department of Pharmacology, Basic Medical School, Wuhan University, Donghu Road 169, Wuhan 430071, China. ${ }^{2}$ Department of Orthopaedic
Surgery, Zhongnan Hospital, Wuhan University, Donghu Road 169, Wuhan 430071, China. ${ }^{3}$ Department of Biochemistry, Basic Medical School, Wuhan University, Donghu Road 169, Wuhan 430071, China. ${ }^{4}$ UMR7561 CNRS-UHP, Laboratoire de Physiopathologie et Pharmacologie Articulaires, Faculté de Médecine, Vandoeuvre-lès-Nancy Cedex, Lorraine 54505, France.

Published: 10 May 2013

References

1. Qin J, Shang L, Ping A, Li J, Li X, Yu H, Magdalou J, Chen L, Wang H: TNF/TNFR signal transduction pathway-mediated anti-apoptosis and antiinflammatory effects of sodium ferulate on IL-1 $\beta$-induced rat osteoarthritis chondrocytes in vitro. Arthritis Res Ther 2012, 14:R242.

doi:10.1186/ar4225

Cite this article as: Qin J, et al.: Correction:TNF/TNFR signal transduction pathway-mediated anti-apoptosis and anti-inflammatory effects of sodium ferulate on IL-1 $\beta$-induced rat osteoarthritis chondrocytes in vitro. Arthritis Research \& Therapy 2013, 15:407.

Equal contributors

*Correspondence: wanghui19@whu.edu.cn; lbchen@whu.edu.cn

'Department of Pharmacology, Basic Medical School, Wuhan University, Donghu Road 169, Wuhan 430071, China

2Department of Orthopaedic Surgery, Zhongnan Hospital, Wuhan University,

Donghu Road 169, Wuhan 430071, China

Full list of author information is available at the end of the article 